\title{
Técnica Modificada de Injerto de Tejido Conectivo Interposicionado y Sobrepuesto en Implantología y Rehabilitación Oral. Reporte de Dos Casos Clínicos
}

\author{
Description of Two Clinical Cases Showing Surgical Possibilities \\ of Correction or Ridges Reconstruction, Using Connective \\ Tissue Graft and Gingival Sculping
}

Javer ME $\mathrm{ME}^{1,2,4,5}$,Godoy CC $1,2,4,5$, López VC

\begin{abstract}
RESUMEN
Se describen dos reportes de casos clínicos mostrando posibilidades quirúrgicas de corrección o reconstrucción para rebordes usando tejido conectivo y posterior modelado gingival.

Rev. Clin. Periodoncia Implantol. Rehábil. Oral Vol. 3(1); 43-50, 2010.
\end{abstract}

Palabras clave: Injerto tejido conectivo, defecto óseo alveolar, injerto sobrepuesto, injerto interposicionado.

\section{ABSTRACT}

Description of two clinical cases showing surgical possibilities of correction or ridges reconstruction, using connective tissue graft and gingival sculping. Rev. Clin. Periodoncia Implantol. Rehábil. Oral Vol. 3(1); 43-50, 2010.

Key words: Onlay graft, connective tissue graft, interpositional graft, alveolar ridge deformities, localized alveolar ridge augmentation, gingival sculping.

\section{INTRODUCCIÓN}

En los últimos años el factor de sobrevida de los implantes ha mejorado progresivamente, y la osteointegración es una realidad desde un punto de vista biológico y la práctica clínica diaria. Estando muy bien respaldado en la literatura actual, no sucede lo mismo con el comportamiento y dinámica de los tejidos blandos peri-implantarios. Es relevante el conocimiento de los factores clínicos y del paciente que influyen en la predictibilidad estética de los implantes osteointegrados. Las variables clínicas incluyen angulación y posición 3D del implante, y el correcto contorno anatómico de la corona provisoria para el modelado de los tejidos blandos. Dependientes del paciente se agregan nivel y grosor óseo alveolar, la relación tejidos blandos-tejidos duros y el biotipo gingival ${ }^{(1,2,3)}$.

De este modo la transformación de un sitio desfavorable a uno favorable es un requisito fundamental en alcanzar adecuados objetivos estéticos. Sin embargo la toma de decisiones y el criterio clínico certero continúan siendo peldaños ineludibles en la elección de una determinada terapia, por lo que hay que evitar la sobre-indicación especialmente de la implantología oral del sector antero-superior, ya que dado su grado de dificultad acarrea resultados que no son muchas veces positivos. Recesiones de la mucosa peri-implantaria y pérdida de la tabla vestibular por excesiva inclinación de los implantes hacia facial y/o detrimento de los tejidos papilares interproximales y reabsorción de la cresta ósea alveolar por una inapropiada posición mesio-distal ${ }^{(3,4)}$. Algo similar sucede cuando no se elige el implante adecuado en cuanto a su largo y ancho. Las prótesis fijas plurales deben constituir alternativas reales cuando el estado de los pilares amerita la confección de una preparación biológica como consecuencia de su compromiso (caries extensas, grandes restauraciones, anomalías anatómicas, traumáticas, etc...). A su vez los vanos tienen que cumplir las condiciones que nos permitan simular con la rehabilitación el máximo de estética relacionada con las características anatómicas de la encía adyacente, en cuanto a cantidad, calidad, textura, color, festoneo y biotipo gingival, lo que se logra a través de una estructura ósea alveolar que sustente una apropiada reconstrucción y preservación de los tejidos blandos del reborde. Por tal motivo es necesario implementar una serie de medidas terapéuticas preventivas y regenerativas cuya filosofía varía dependiendo del tiempo transcurrido desde la pérdida de las piezas, por lo que el enfoque va a ser distinto cuando se pretende la conservación de un sitio post-extracción o cambia cuando el proceso residual lleva tiempo desdentado y se pretende instalar un implante o una prótesis fija plural. Por ejemplo en el momento de la extracción es imprescindible desarrollar y mantener el volumen del sitio en base a los cánones de cirugía plástica periodontal e implantológica, implicando la utilización de injertos duros y/o blandos ${ }^{(6,7)}$. Además la armonía morfológica de los tejidos gingivales como factor determinante, se consigue a través de la forma de la restauración provisional que va estar involucrada directamente en el moldeado y conformación del tejido durante el proceso de cicatrización, que servirá como una guía para posteriormente incorporar los contornos a la restauración definitiva y permitirá la creación de perfiles de emergencia de mayor naturalidad, procedimiento denominado "sculping o modelado gingival" $(5,6,7,8)$. Uno de los más utilizado es el de los pónticos ovales que se emplea tanto en moldeado de zonas para implantes o para prótesis fijas convencionales. Los factores de estética y/o función determinarán el pronóstico terapéutico en las opciones de tratamiento de los rebordes alveolares y la combinación de injertos duros y/o blandos manejados e indicados en forma adecuada reducirán estos defectos ${ }^{(18,19,20,21)}$.

\section{Especialista en Periodoncia. Chile.}

2. Especialista en Implantología Oral. Chile.

3. Profesor Adjunto, Programa de Especialización en Periodoncia, Unidad de Cirugía Plástica Periodontal e implantológica, Escuela de Graduados, Facultad de Odontología, Universidad de Chile. Chile.

4. Docente, Programa de Especialización en Periodoncia, Unidad de Cirugía Plástica Periodontal e Implantológica, Facultad de Odontología, Universidad de Chile. Chile.

5. Docente Curso "Cirugía Plástica Periodontal e Implantológica", Facultad de Odontología, Universidad de Chile. Chile. 
En general los de tipo leve a moderado pueden ser solucionados con injertos de tejidos blandos y los más severos requieren de combinaciones de tejidos duros y blandos ${ }^{(9,10,11,12)}$. En la elección de la técnica influye también el tipo de tratamiento. Si la rehabilitación es en base a prótesis fija plural (PFP) el aumento con injertos blandos podría ser suficiente sin embargo para implantes la reconstrucciones en la mayoría de los casos requiere tantos tejidos blandos y duros ${ }^{(13,14,15,16,17,22)}$.

Los casos clínicos que se presentan a continuación son:

-Técnica modificada de injerto de tejido conectivo interposicionado y sobrepuesto más una prótesis fija plural, para solucionar estéticamente una problemática de posición de un implante osteo-integrado.

-Técnica de injerto de tejido conectivo interposicionado más un sculping de tejidos blandos con una rehabilitación fija plural.

\section{CASO CLÍNICO 1}

Técnica modificada de injerto de tejido conectivo interposicionado y sobrepuesto más una prótesis fija plural, para solucionar estéticamente una problemática de posición de un implante osteointegrado

Paciente JG de sexo femenino de 35 años, sin antecedentes de enfermedades sistémicas consulta por solución estética de implante oseointegrado en zona de diente 2.2 (pieza 10), que está conectado con pilar definitivo y corona provisoria, hace 6 años (Figura 1A). La paciente no ha terminado su rehabilitación por disconformidad con los resultados estéticos, evidenciando alteraciones posicionales y de arquitectura gingival (Figura 2A). Se solicitaron radiografías retroalveolares periapicales y scanner cone beam tipo I-Cat ${ }^{\circledR}$ (Figuras $3 A$ y $4 A$ ), observándose una franca posición alta y vestibular de la plataforma del implante que imposibilita rehabilitarlo correctamente de modo que la decisión como plan de tratamiento fue no utilizar el implante oseointegrado, dejándolo sumergido, para así evitar el riesgo estético por el acto quirúrgico. Aprovechando los pilares de inserción protésica, se confeccionó una prótesis fija plural provisional (PFPP), previo retiro del pilar protésico e instalando el tornillo de cierre original del implante previamente esterilizado. Después de 2-3 semanas, se espera un aumento de volúmen gingival alrededor del implante (Figura 5A), similar a lo descrito por Langer, B., en 1994(8) que él llamó "aumento gingival espontáneo in situ" (Figura 6A). Para sumergir el implante, se decidió realizar un procedimiento quirúrgico reconstructivo en base a injerto de tejido conectivo interpuesto-sobrepuesto ${ }^{(1)}$ obtenido de la región palatina.

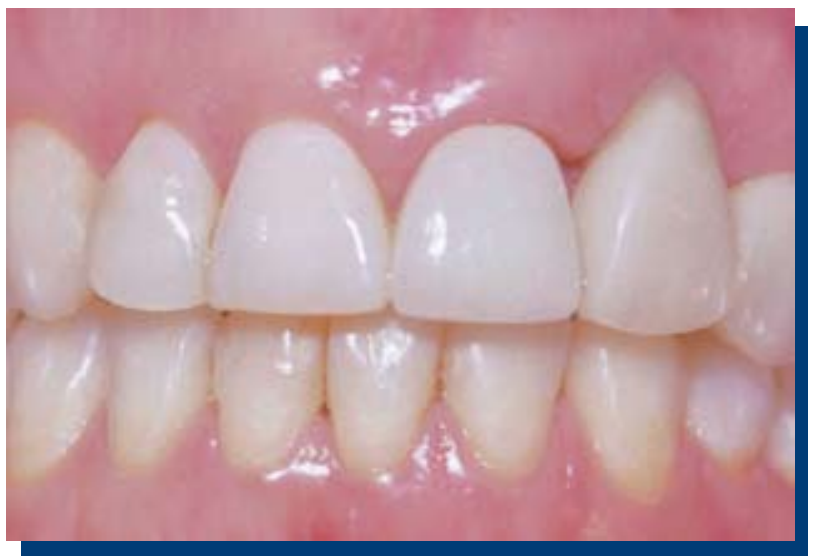

Figura 1A. Paciente con corona provisoria diente 2.2 afectando la estética y arquitectura gingival.

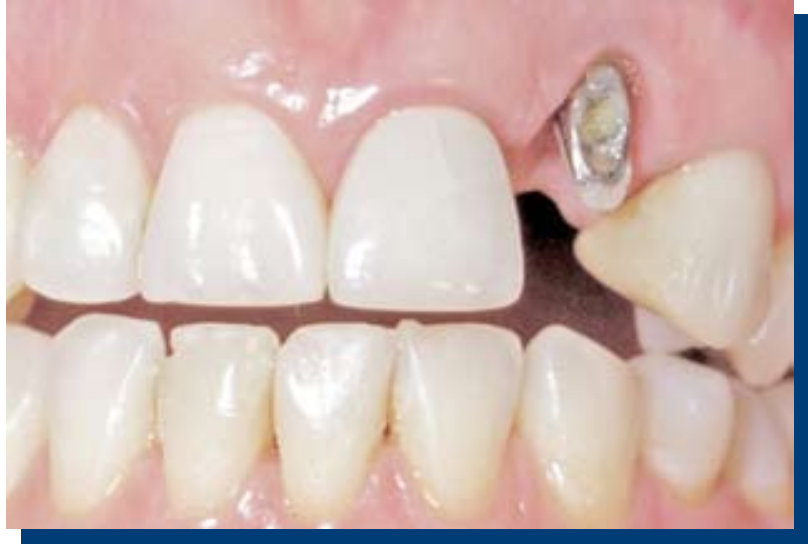

Figura 2A. Posición del pilar evidenciando la imposibilidad de restaurar con resultados estéticos.
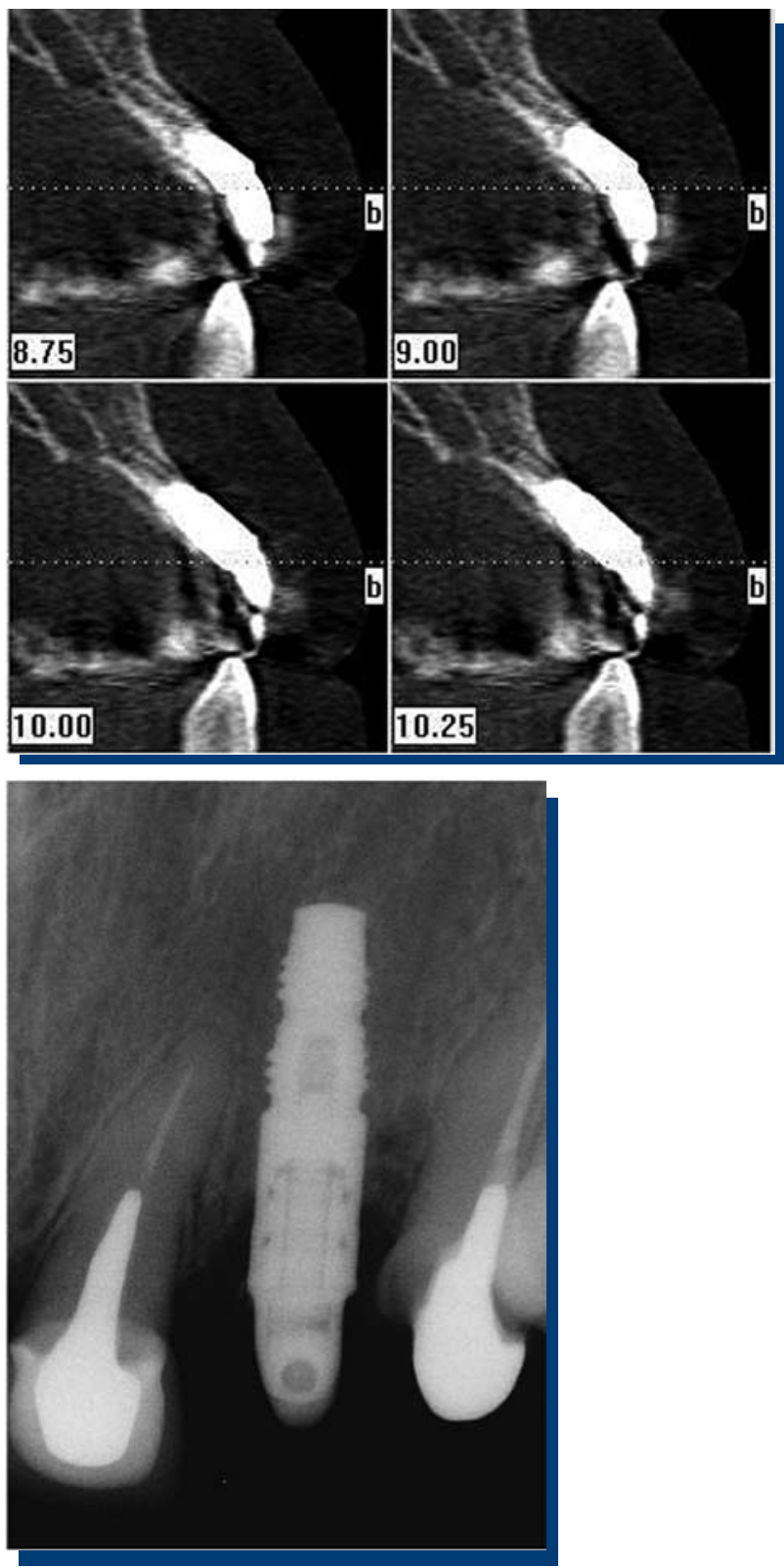

Figuras 3A y 4A. Radiografía retroalveolar periapical y scanner que demuestra ausencia de tabla externa e inclinación anómala del implante. 


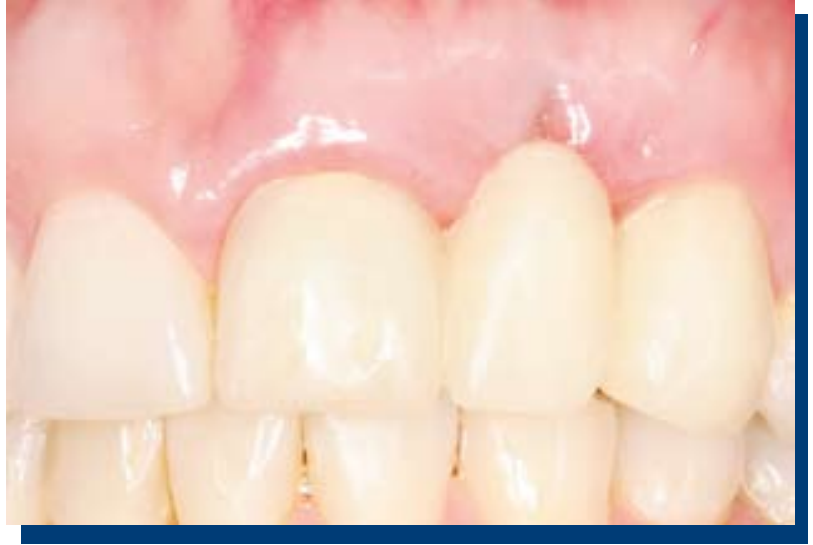

Figura 5A. Prótesis fija plural provisoria y aumento de volumen gingival alrededor del implante después de 3 semanas.

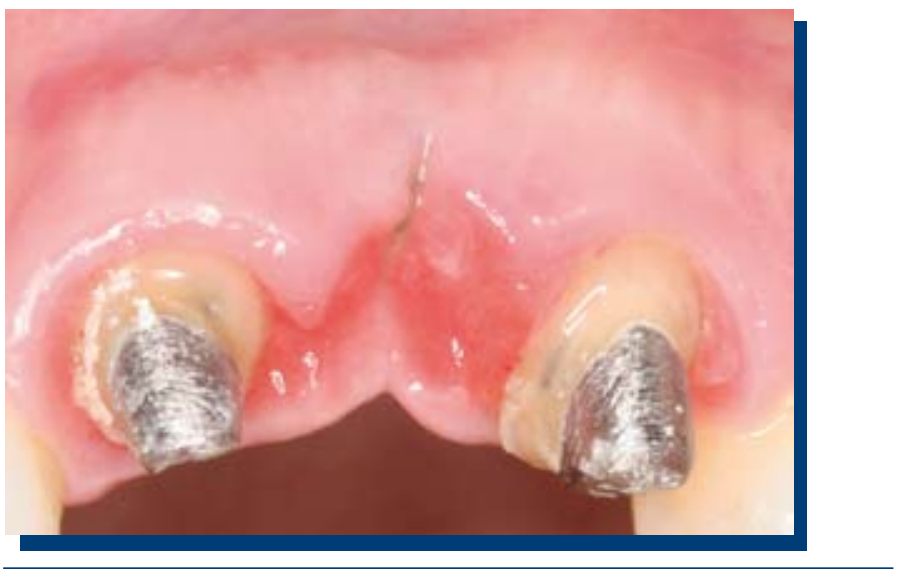

Figura 6A. Crecimiento gingival espontáneo que oculta el tornillo de cierre del implante.

La paciente es premedicada con Clavoxilina ${ }^{\circledR}$ BID $875 \mathrm{mg} / 125$ (Oral Care, Laboratorio Recalcine, Chile), 1 comprimido recubierto cada 12 hrs. por 7 días, con un analgésico, Atac $® 550 \mathrm{mg}$ (Oral Care, Laboratorio Recalcine, Chile) cada 12 hrs. por tres días y colutorios de

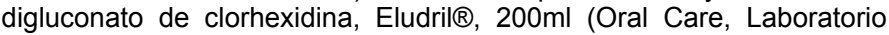
Recalcine, Chile) a partir del día anterior. Previa anestesia infiltrativa (Septanest $₫$, articaina $1 / 100000$, Septodont $₫$, Francia) se inicia la cirugía en el sitio receptor con un colgajo de espesor parcial y diseño de incisiones en " $\mathrm{H}$ " con orientación curva y respetando papilas gingivales de piezas vecinas. La incisión horizontal es en posición paramediana levemente a palatino. Se efectúa un bolsillo de espesor parcial tanto a vestibular como a palatino en una disección en $180^{\circ}$ o en abanico del área; debiendo obligatoriamente sobrepasar la línea mucogingival, siendo éste un punto crítico de la técnica (Figuras $7 \mathrm{~A}$ y $8 \mathrm{~A}$ ). Debido a la excesiva inclinación hacia vestibular del implante, se decide desgastar y pulir la porción aguda de la plataforma en su porción vestibular para dar espacio al injerto de tejido conectivo (Figura 9A).

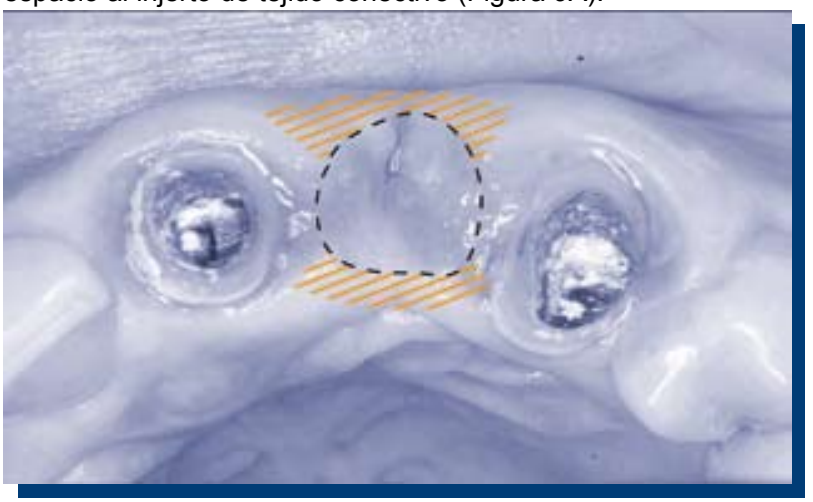

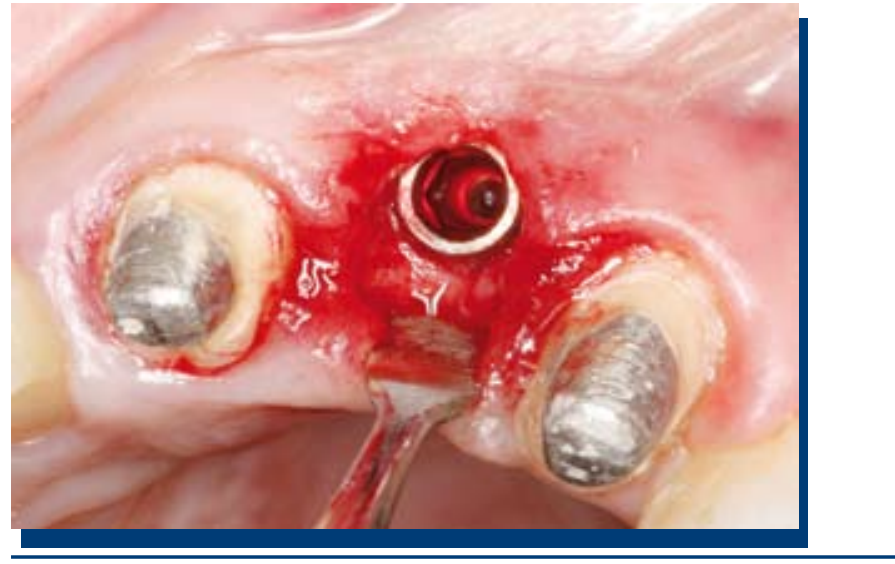

Figuras 7A y 8A. Incisiones en "H" con tunelización (ver achurado), sobrepasando en vestibular la unión mucogingival, punto crítico en la técnica.

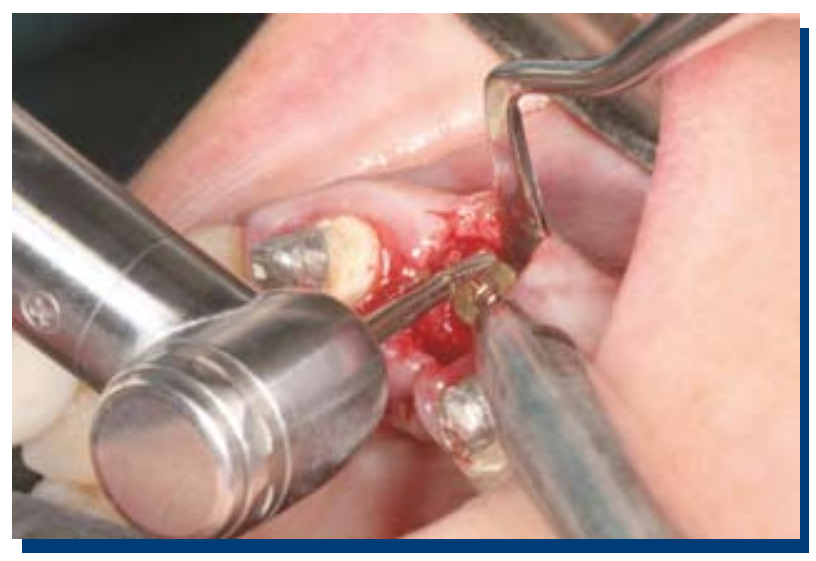

Figura 9A. Desgaste de la porción aguda de la plataforma del implante para crear espacio al injerto de tejido conectivo.

Para la toma del injerto palatino se utilizó un bisturí 15C (Salvin $®, U S A$ ), realizando dos incisiones paralelas en dirección anteroposterior hasta contacto óseo, separadas $10 \mathrm{~mm}$ y alejadas de 2-3 mm del margen gingival de primer molar y premolares. Se contornea una zona central que preserva un círculo de epitelio palatino y dos colgajos laterales de disección parcial epitelizados. El tamaño y volumen del injerto, está determinado por la boca de entrada de la incisión de la zona receptora. Por ende, el aspecto de este injerto de tejido conectivo asemeja una porción epitelizada central circular con dos extensiones laterales de tejido conectivo (Figura 10A). Una vez acondicionado el injerto, se procede a posicionarlo y fijarlo en la zona receptora, introduciendo primero una porción conectiva en el bolsillo vestibular con sutura tipo colchonero horizontal y luego se introduce la otra porción conectiva en el bolsillo palatino, con otra sutura de tipo colchonero horizontal. Finalmente se procedió suturar la porción epitelial circular en los bordes de la herida con suturas en "O" interrumpidas, y sutura colchonero horizontal cruzado suspensorio de vestibular a palatino para estabilizar el injerto. El material utilizado en las diversas etapas fue Polysorb $\AA$ reabsorbible $5-0$, aguja $1 / 2$ de $16 \mathrm{~mm}$, reverso cortante (Syneture ${ }^{\circledR}$, USA), (Figuras $11 \mathrm{~A}$ y $12 \mathrm{~A}$ ).

El sitio dador fue fijado con suturas tipo colchonero horizontal cruzado con ancla dentaria por vestibular y la prótesis fija plura provisoria se desgasta lo necesario para evitar sobrecompresión de la herida (Figura 13A).

La paciente fue instruída para evitar el cepillado de la zona intervenida por 15 días y colutorios de digluconato de clorhexidina, Eludril $囚, 200 \mathrm{ml}$ (Oral Care, Laboratorio Recalcine, Chile) por 14 días. Los controles se realizaron a los dos días, a la semana, a los 15 días, al mes, 2, 3, 4 y 6 meses. En cada visita, se aplicaron lavados de digluconato de clorhexidina y acondicionamiento del provisorio, especialmente a nivel del póntico oval (Figuras 14A y 15A). 


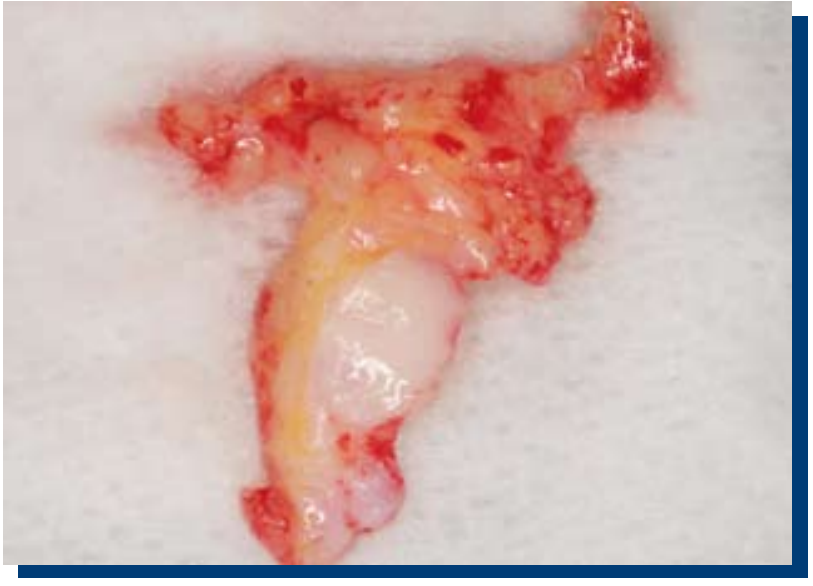

Figura 10A. Injerto de tejido conectivo palatino con una porción epitelial circular en su porción central.
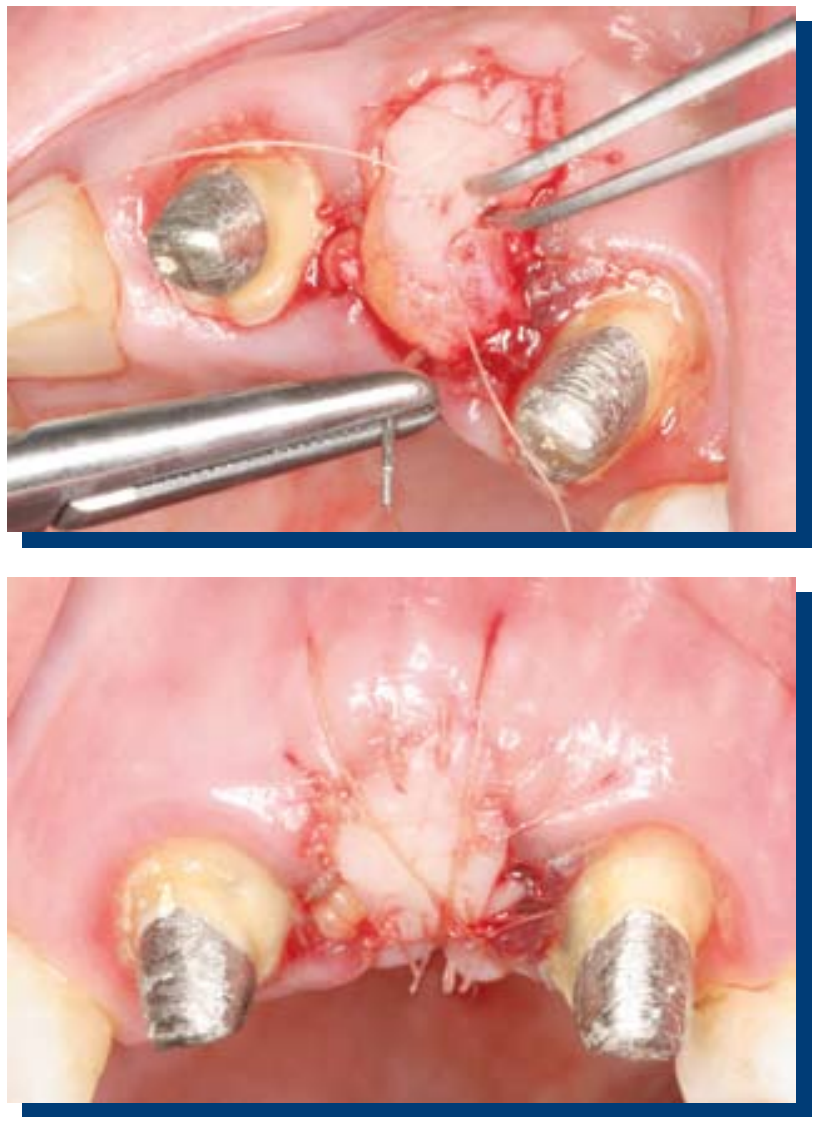

Figuras 11A y 12A. Luego de suturar el conectivo en los túneles vestibular y palatino con colchoneros horizontales se sutura el área circular del epitelio palatino en la porción central del reborde, sobre el tornillo de cierre del implante.

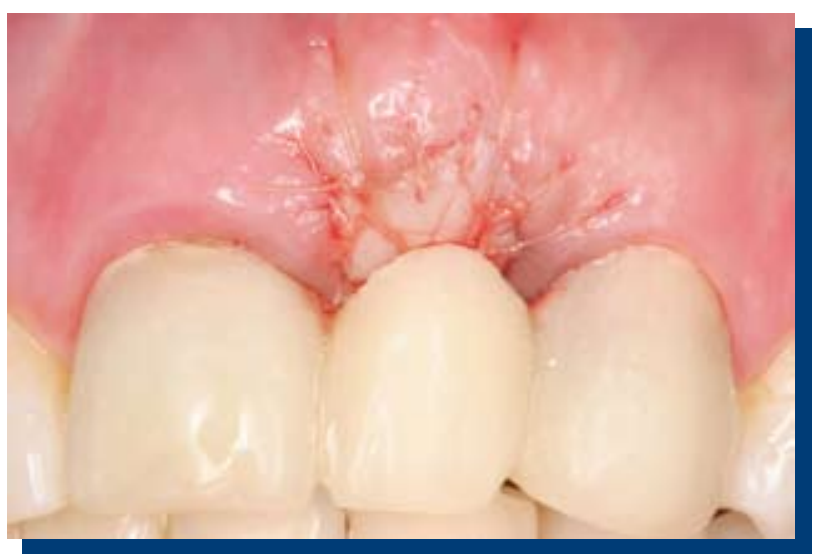

Figura 13A. El póntico se desgasta manteniendo su forma oval pero evitando la sobrecompresión de la mucosa.

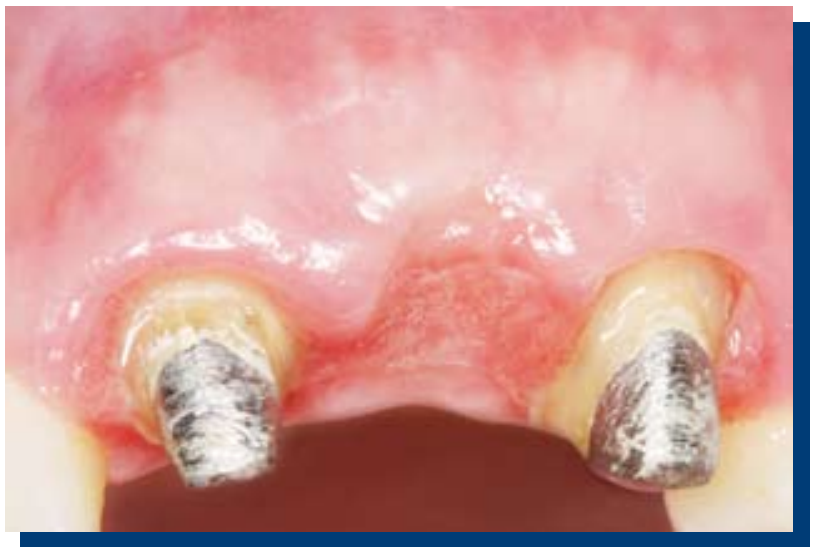

Figura 14A. Post- operatorio a los 4 meses vista frontal.

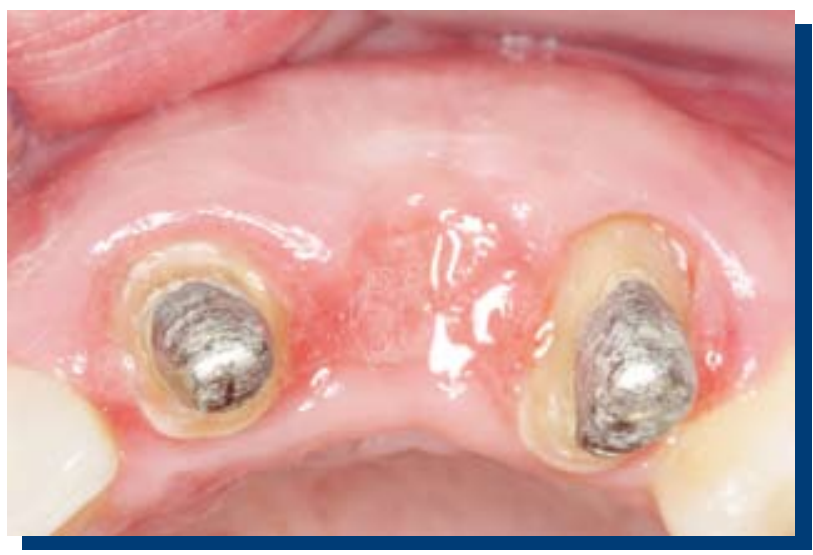

Figura 15A. Post-operatorio a los 6 meses vista oclusal, con impronta del diente con el póntico oval.

\section{CASO CLÍNICO 2}

Técnica de injerto de tejido conectivo interposicionado más un sculping de tejidos blandos con una rehabilitación fija plural

Paciente sexo femenino 34 años, portadora de prótesis fija plural (PFP) metal- cerámica en el sector anterosuperior desde diez años a la fecha, pilares piezas 1.1 y 2.2 tratadas endodónticamente, póntico pieza 2.1, consulta por disconformidad estética, ya que, en sus palabras , se le ve "hundida" y "oscura" la zona de encía sobre la prótesis. Al examen clínico se aprecia gran desajuste cervical y evidente colapso vestibular del reborde sobre el póntico con compromiso vertical zona pieza 2.1 (Figura 1B), clase III de Siebert. Como plan de tratamiento, se propone el cambio de la estructura aprovechando los pilares ya existentes por una PFP libre de metal más desarrollo de sitio en base a injerto de tejido conectivo sub epitelial interpuesto sobrepuesto 
sobredimensionando su volumen ("concepto de overbuilding") , tratando de compensar la contracción final del tejido injertado, usando como zona dadora el paladar de la paciente ${ }^{(21)}$.

Al remover la antigua estructura para provisionalizar, se aprecia conservado el remanente dentario, procediendo a su refuerzo con espigas de fibra de vidrio cementadas con resina Unicem ${ }^{\circledR}(3 \mathrm{M} \AA$, USA) luego de instalado provisorio acrílico con refuerzo metálico (Figura 2B), se programa una cirugía reconstructiva para mejorar condición en sentido horizontal y vertical del reborde.

La paciente es premedicada con Clavoxilina ${ }^{\circledR}$ BID $875 \mathrm{mg} / 125$ (Oral Care, Laboratorio Recalcine, Chile), 1 comprimido recubierto cada 12 hrs. por 7 días, con un analgésico, Atac® 550mg (Oral Care, Laboratorio Recalcine, Chile) cada 12 hrs. por tres días y colutorios de digluconato de clorhexidina, Eludril $(200 \mathrm{ml}$ (Oral Care, Laboratorio Recalcine, Chile) a partir del día anterior.

El diseño del colgajo se efectúa en espesor parcial conservador a capa superficial, respetando las papilas gingivales de piezas vecinas, y asegurando la irrigación y posición de las mismas (Figura 3B), debemos mantener un grosor en homogéneo en toda la extensión del colgajo, pasando la línea muco gingival en sentido apical y tunelizando en sentido mesial y distal lo suficiente para esfumar el borde del injerto (Figura 4B), logrando un bolsillo uniforme para albergar al tejido conectivo el cual se tracciona en un vector de fuerza vertical con sutura reabsorbible 5-0 (Polysorb $\AA$, aguja $1 / 216 \mathrm{~mm}$, reverso cortante, Syneture ${ }^{\circledR}$, USA), desde vestibular (Figura 5B). Considerar el punto de entrada de la sutura (colchonero horizontal), en relación a la cantidad de injerto que queramos sumergir para terminar cerrando con puntos simples de estabilización (Figuras 6B y 7B). Se alivia el talón del póntico provisional acrílico para no interferir con la cicatrización y ganancia de volumen por sobre compresión de la zona antes de su cementación temporal (Figura 8B y 9B). Si es necesario repetir el procedimiento en los días inmediatamente posteriores a la cirugía, se deja la sutura durante 14 días y cicatrizar los tejidos durante 45 antes de empezar el modelado gingival o "sculping gingival" de la zona, por medio de sobrecompresión gradual en forma de un póntico oval, agregando composite $Z 350 \AA(3 \mathrm{M} \otimes$, USA) directamente al talón del póntico (Figuras 10B,11B y 12B), proceso que debe tomar dos a cuatro semanas (Figura 13B), para luego, dejar madurar los tejidos finalmente durante dos meses (Figura 14B), dando un total de cinco meses aproximadamente desde efectuada la cirugía, hasta obtener estabilidad volumétrica en el tiempo antes de tomar la impresión (Figura 15B) para la prótesis definitiva (Figuras 16B,17B,18B y 19B).

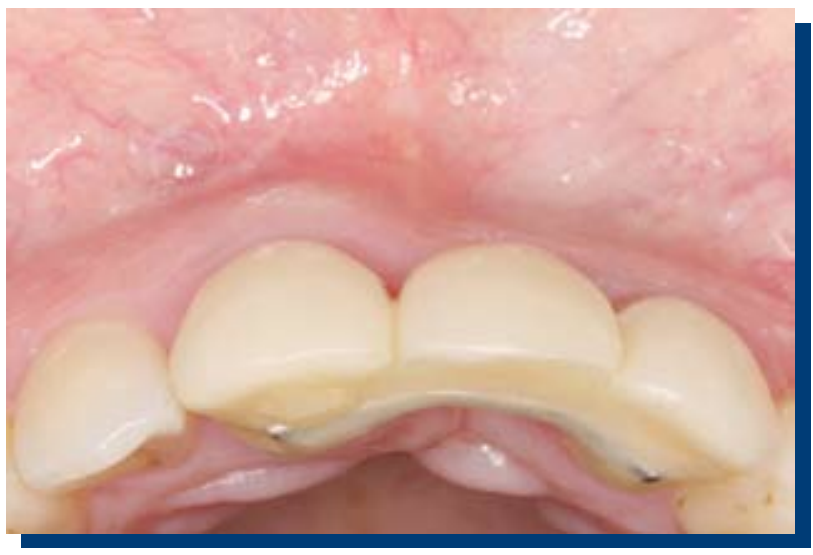

Figura 1B. Defecto vestibular con pérdida de volumen reborde.

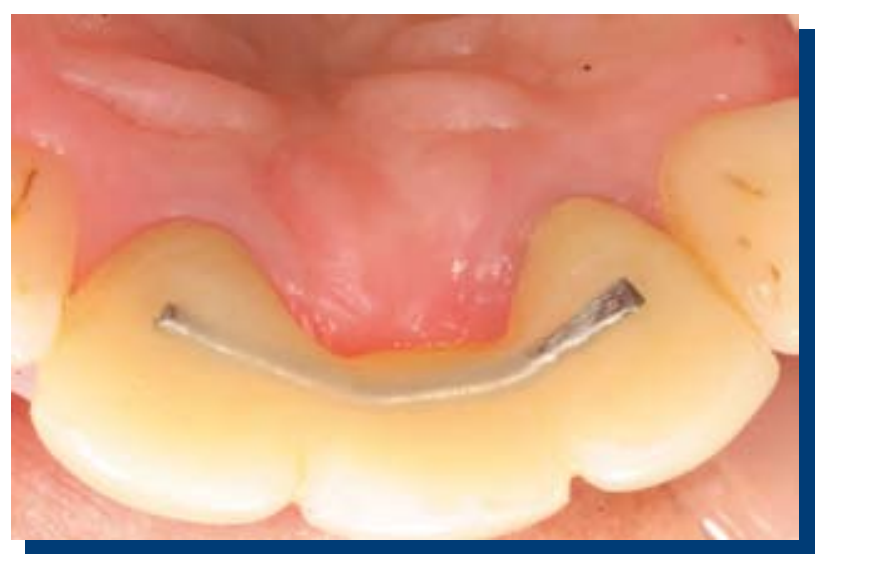

Figura 2B. Vista palatina de provisional con refuerzo metálico.

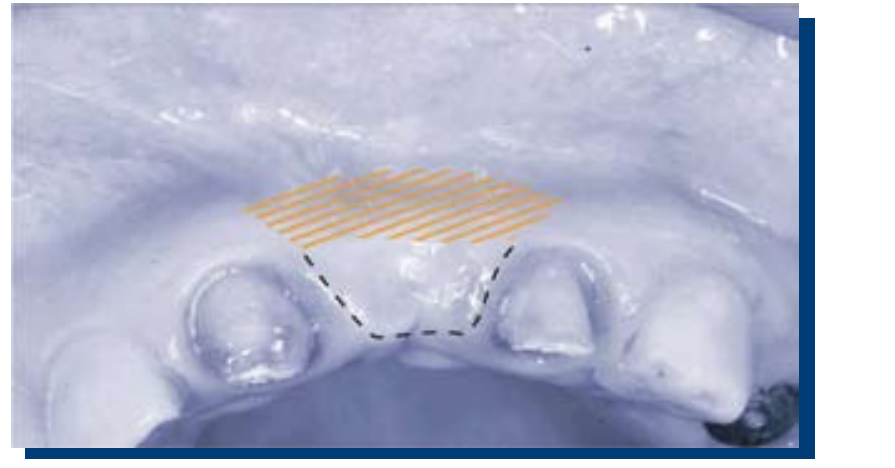

Figura 3B. Diseño de colgajo espesor parcial respetando papilas piezas vecinas.

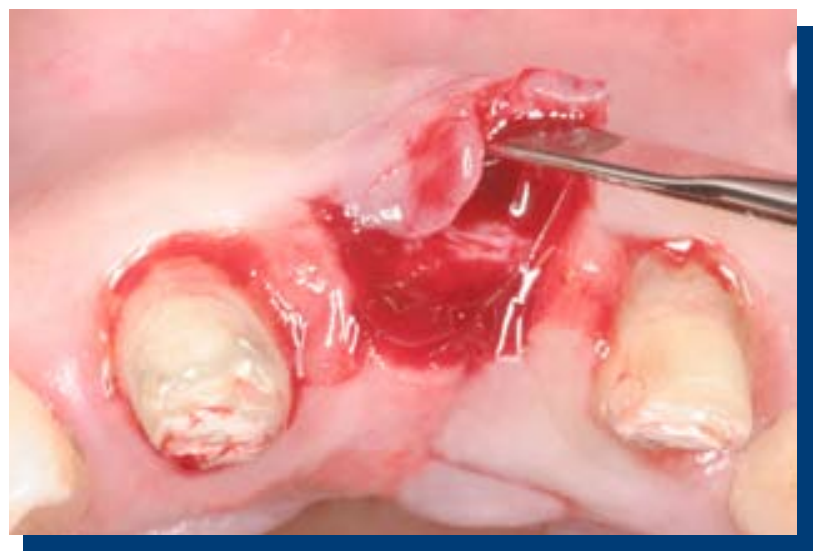

Figura 4B. Colgajo levantado.

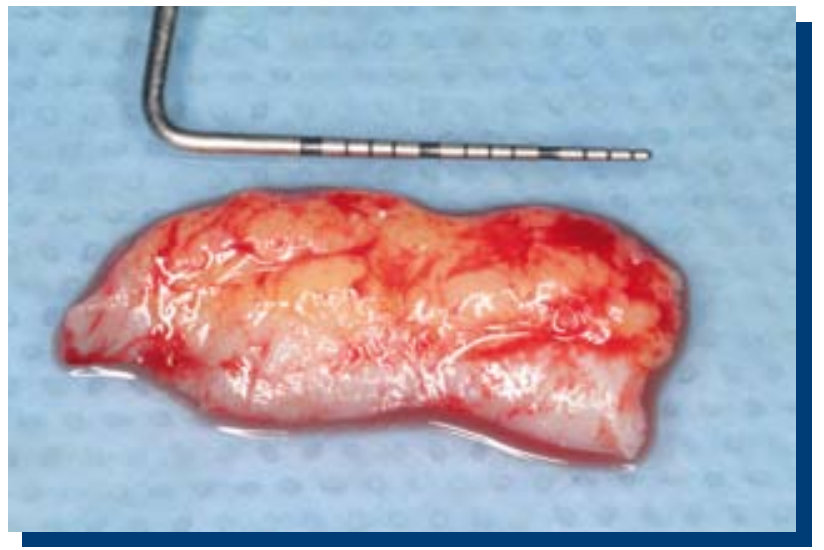

Figura 5B. Injerto conectivo palatino. 

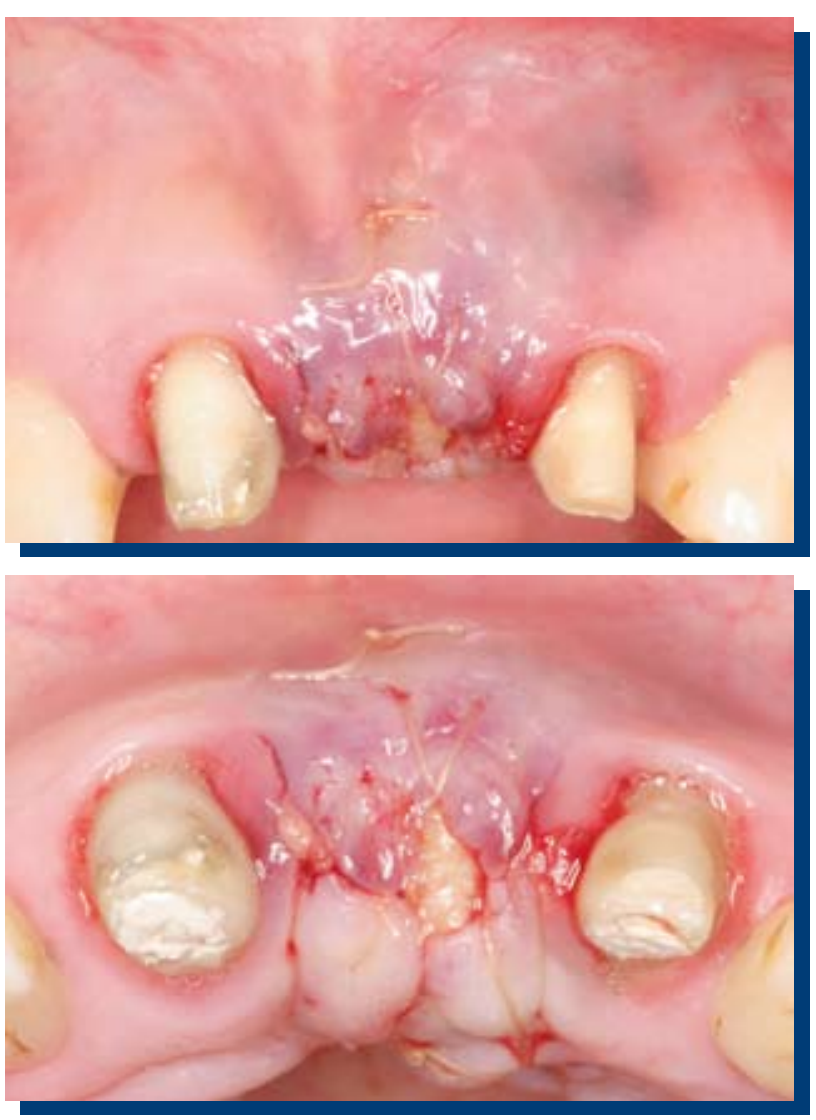

Figuras 6B y 7B. Injerto en posición anudada con sutura de tracción vestibular.
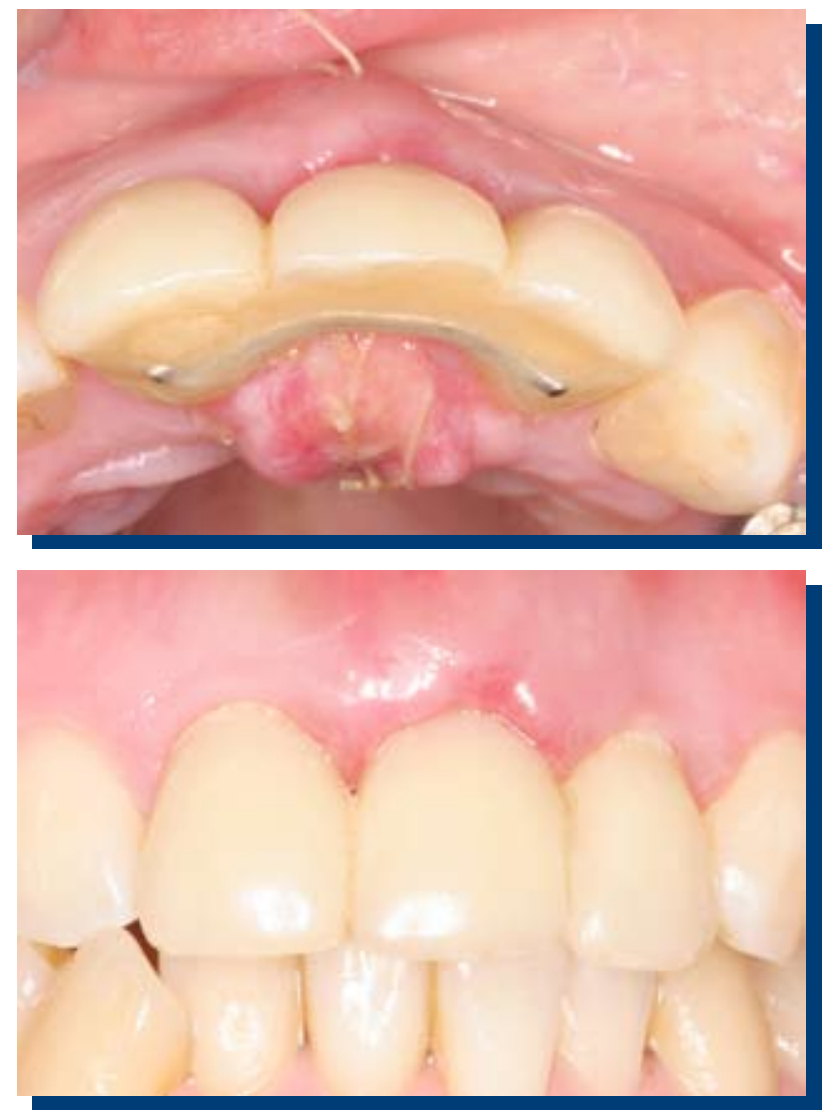

Figuras 8B y 9B. Provisional aliviado en su talón evitando sobrecompresión, se aprecia reconstrucción con sobrecontorno "overbuilding".
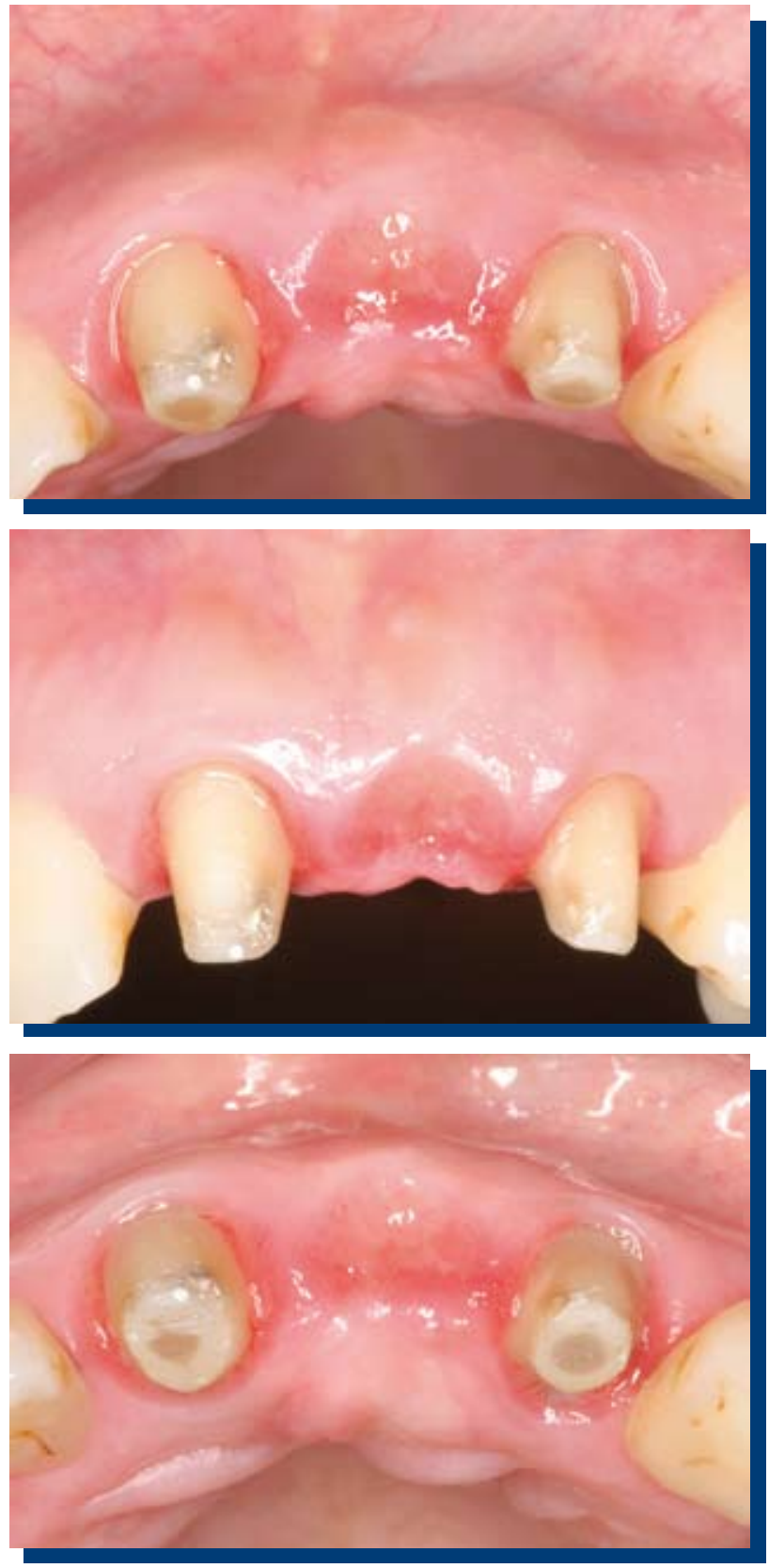

Figuras 10B, 11B y 12B. Modelado gingival "sculping".

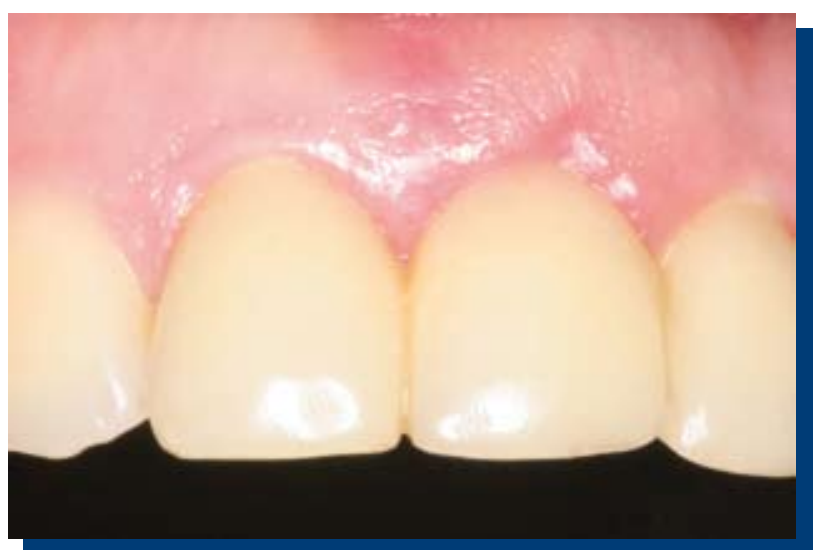

Figura 13B. Modelado terminado en etapa de estabilización o maduración de tejido. 


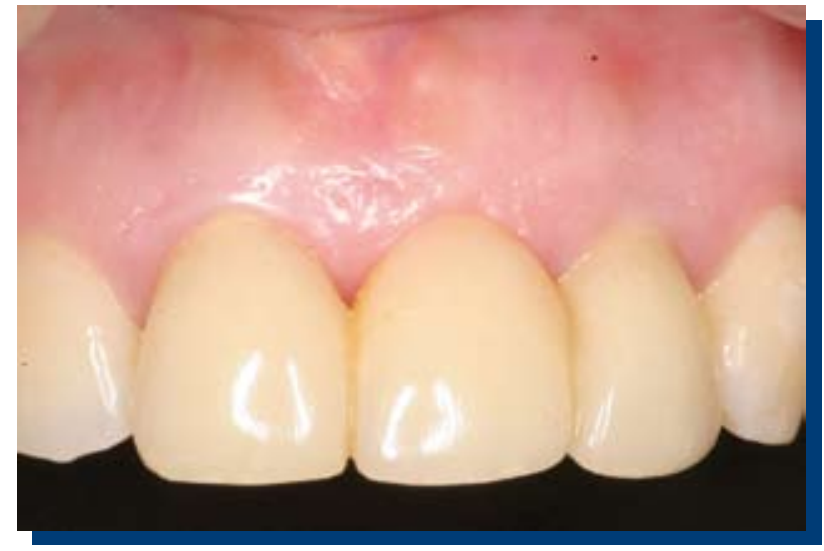

Figura 14B. A seis meses de la cirugía el tejido muestra la estabilidad volumétrica.

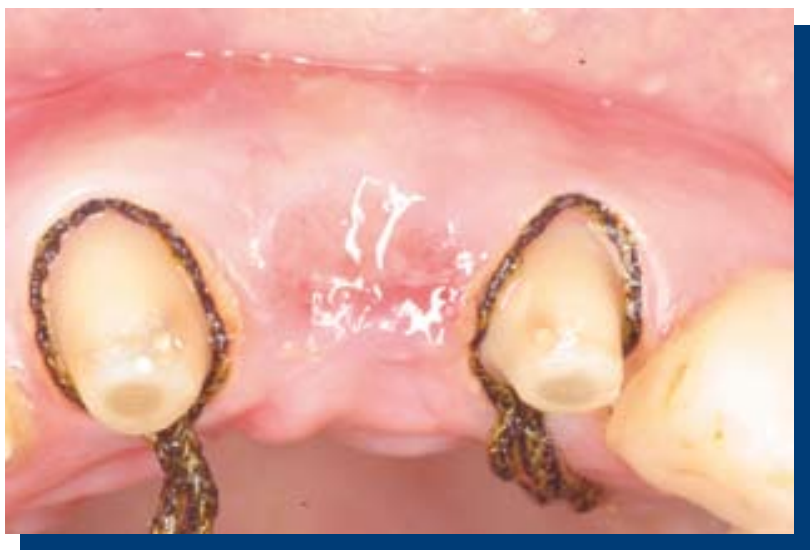

Figura 15B. Pilares preparados para impresión definitiva.

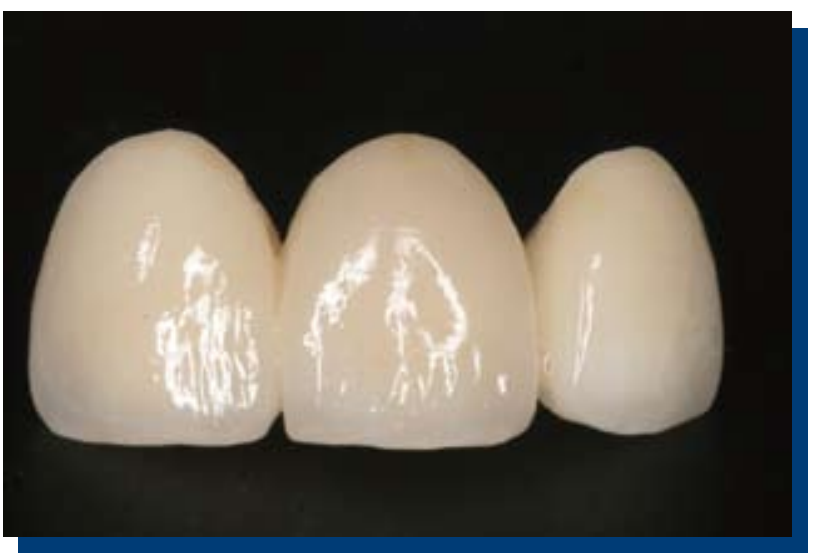

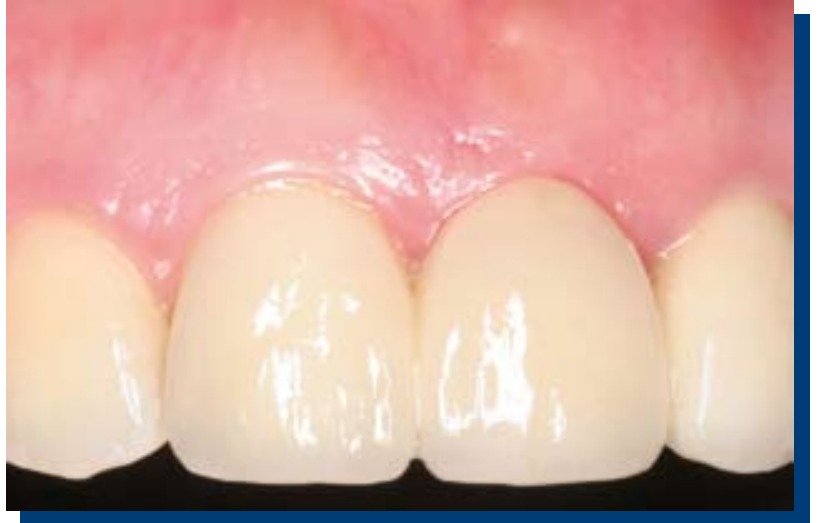

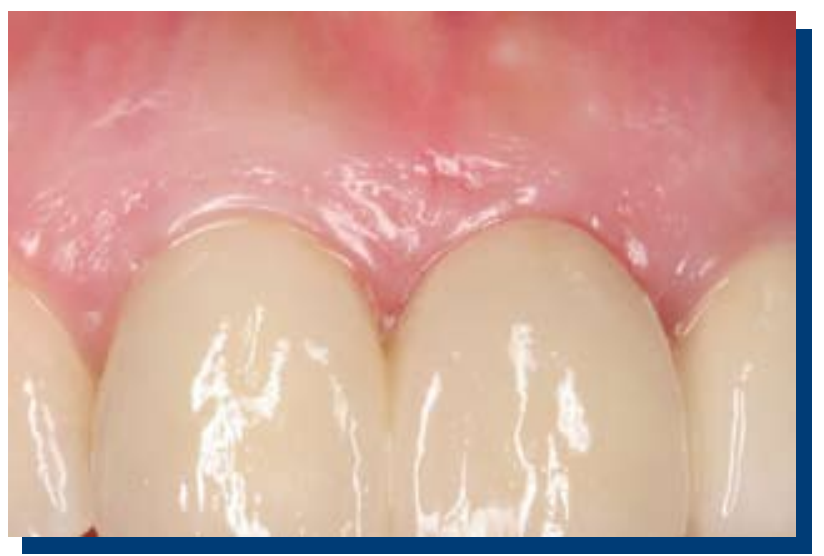

Figuras 16B, 17B y 18B. Estructura de PFP libre de metal en posición y cementada.

\section{CONCLUSIÓN}

Dentro de los conceptos clínicos-biológicos en rehabilitación oral, el manejo correcto de los tejidos blandos de la mucosa perimplantaria o de los pónticos a través de su modelado sistemático y consecutivo, respetando los timing de cicatrización en la temporalización es una poderosa herramienta terapéutica para alcanzar una adecuada armonía estética dento-gingivo-facial.

\section{REFERENCIAS BIBLIOGRÁFICAS}

1. Cairo F, Pagliaro U, Nieri M. Soft tissue management at implant sites. J Clin Periodontol 2008; 35 (Suppl. 8): 163-167.

2. Berglundh T, Abrahamsson I, Welander M, Lang NP, Lindhe J. Morphogenesis of the peri-implant mucosa: an experimental study in dogs. Clin Oral Impl Res 2007; 18:1-8

3. Pini Prato, G P, Cairo, F, Tinti, C, Cortellini, P, Muzzi, L \& Mancini, E A.Prevention of alveolar ridge deformities and reconstruction of lost anatomy: a review of surgical approaches. Int J Periodontics Restorative Dent 2004; 24: 434-445.

4. Pini Prato, G P, Clauser, C \& Cortellini, P. Periodontal plastic and mucogingival surgery. Periodontology 2000 1995; 9: 90-105.
5. Harvey B. Optimizing esthetic potencial of implant restorations through the use of inmediate implants with inmediate provisionals. J Periodonto 2007; 78:770-776.

6. Kan J, Rungcharassaeng K, Lozada J. Immediate Placement and provisionalization of maxillary anterior single implants:1-year prospective study. Int J Oral Maxillofac Implants 2003;18:31-39.

7. Jemt T, Patterson P. A 3-year follow-up study on single implant treatment. Dentistry 1993;21:203-208.

8. Langer B. Spontaneous in situ gingival augmentation. Int J Periodontics Restorative Dent 1994; 6:525-536.

9. Wennström J, Pini Prato GP. Mucogingival therapy—Periodontal plastic 
surgery. In:Lindhe J, Karring T, Lang NP (eds). Clinical Periodontology and Implant Dentistry, ed 4. Oxford, UK: Blackwell Munksgaard, 2003.

10. Seibert JS. Reconstruction of deformed, partially edentulous ridges, using full thickness onlay grafts. Part I. Technique and wound healing. Compend Contin Educ Dent 1983;4:437-453.

11. Allen EP, Gainza CS, Farthing GG, Newbold DA. Improved technique for localized ridge augmentation. A report of 21 cases. J Periodontol 1985;56:195-199.

12. Studer $S$, Naef R, Schärer $P$. Amélioration esthétique des pertes de substance. Intérêt de la chirurgie mucogingivale. Clinic 1998;19:547-561.

13. Seibert JS, Salama H. Alveolar ridge preservation and reconstruction. Periodontol 2000 1996;11:69-84.

14. Miller PD Jr. Periodontal plastic surgery. Curr Opin Periodontol 1993:136-143.

15. Scharf DR, Tarnow DP. Modified roll technique for localized alveolar ridge augmentation. Int J Periodontics Restorative Dent 1992;12:415-425.

16. Langer B, Calagna L. The subepithelial connective tissue graft. J Prosthet Dent 1980;44:363-367.
17. Kaldhal WB, Tussing GJ, Wentz FM, Walker JA. Achieving an esthetic appearance with fixed prosthesis by submucosal graft. J Am Dent Assoc 1982;104:449-452.

18. Meltzer JA. Edentulous area tissue graft correction of an esthetic defect. A case report. J Periodontol 1979;50:320-322.

19. Seibert JS. Soft tissue grafts in periodontics. In: Robinson PJ, Guersney LH (eds). Clinical Transplantation in Dental Specialties. St Louis: Mosby, 1980:107-145.

20. Seibert JS, Louis J. Soft tissue ridge augmentation procedure utilizing a combination onlay-interpositional graft procedure: Case report. Int $\mathrm{J}$ Periodontics Restorative Dent 1996;16:311-321.

21. Fickl S, Zuhr O, Wachtel H, Kebschull M, Hurzeler MB. Hard tissue alterations after socket preservation with additional buccal overbuilding: a study in the beagle dog. J Clin Periodontol 2009;36: 898-904.

22. Godoy C, Javer E, Caffarena R, López C. Aumento tridimensional de un reborde alveolar mediante una técnica modificada de injerto de tejido conectivo interposicionado y sobrepuesto. Rev Clin Period Implantol Rehab Oral 2008;1:27-31. 